\title{
The "question of the technique": from the designing idea to the realized form
}

\author{
R. Panei \\ Department of Building and Heritages, AMA, Rome, Italy \\ P. Trovalusci, A. Tinelli \\ Department of Structural and Geotechnical Engineering, Sapienza, University of Rome, Rome, Italy
}

\begin{abstract}
This work aims at focusing the inner relationship between the formal intuition of the design process and the structural/technological boundaries behind the creation of any architectural constructed form. Through the analysis of some noteworthy architectural examples, we highlight the reasons for which their designers achieved a virtuous equilibrium between shape, design and constructive awareness. In a contemporary era in which the major architectural production seems more interested to show off and amaze the spectators with huge scales and charming contaminations from the entertainment industry, a call for the need of the Vitruvian lesson appears essentials: the more we push our creativity as designers, the more we need to keep it firmly stick to the principles of firmitas, utilitas and venustas.
\end{abstract}

\section{INTRODUCTION}

A key point of this investigation is the concept of governing technical instrumentation (building technology but, nowadays, also electronic instrumentation and software) in order to realize architecture as faithful as possible to the original designing idea.

In the architectures of the past (pre-electronic era) the technological development, also recently supported by structural mechanics knowledge, promoted and influenced the invention of the constructed forms often taking on new daring forms. In most cases, the project idea strictly correspons to the realized buildings as a result of the awareness of the construction technique. By contrast at present, the possibility to create new shapes is completely governed by the digital design, (and) in some successful cases with the structural support of optimal design. The project idea hardly corresponds to the realized form which, often escaping the control of the designer, results as the repetitive outcome of a mathematical exercise using software instruments.

In this work the specific case of contemporary architectures (by Mies van der Rohe, Le Corbusier, T. Ito, etc.) are analyzed as paradigmatic examples in which the essence of the technique is unveiled by the recognition of a 'regulating principle' (inspired to L.B. Alberti first up to Le Corbusier [8], Cesare Brandi [2], Vittorio Gregotti [6,7] and others), which allows the control of the architectural process from its start on the basis of fruitful, synchronic, interrelation among the Vitruvian components of architecture. Such a principle of inner coherence and necessity of the work to realize, together with a well aware support of technical instrumentation, appears as the common threads which enabled the designers of these works to carry out and convincingly finalize their research. More pragmatically, this means that, from the beginning of the process, the designers seem to already know what they were looking for and, paraphrasing a sentence of the music composer Pierre Boulez [1], once they reached the end of their work, their greatest satisfaction was to recognize that the result corresponded to the one that, before starting, they had thought and imagined. 


\section{THE 'RECOVERED' SHAPE}

When at the end of the process from the designing shape to the realized form the composer is able to find what he imagined at the beginning of the path, the result is a reason of complete satisfaction [1]. In architecture this happens when the initial scheme, although very concisely, already contains in itself all the aspects to be processed and, after further investigations and developments, this reaches up the completion of the production process. In this case the final realized form remains as much as possible comparable to original designing idea. As in a closing loop, the starting idea - going through all the steps of the project: from the dimensional checks to the structural ones; from the compliance to urban and landscape planning to the sizing of technological systems; from the choice of the materials to the comparison with the construction techniques - returns at end of the cycle, in the synthetic form of the realized object, to look like itself. The final image fits the starting one. The inner coherence shaping an architectural work is the result of this synthetic approach, when it is wisely conducted without hesitations, nor concessions to trends and attractive technologies.

In the next Table we synthetize a sketch of the designing process split into three phases referring to this circular structure.

SKETCH (CONCEPT)
This is the very first deepening of an idea, representation of a will, a desire to
be developed in all of its practical implications, but already extremely clear
and concrete, even in its extremely synthetic form. In a sketch, are condensed
all the choices, even those not completely aware, concerning the form, the
location, the functionality and the technology of the work which the project
is yet to be drawn.
PROJECT
At this stage the skill lies primarily in being able to develop the design
through the path indicated by the synthetic starting sketch idea. This means
deepening the formal, functional, technical and technological aspects in line
with the underlying assumption, with the idea at the base of the project. Too
often, in recent years, this development has been delegated by the designer to
other technicians leaving the control of the choices, inevitably leading to a
different interpretation of the needs and, therefore, to a formal (and
functional) outcome, different from what they originally imagined.
REALtch
ReAliontion
During the execution, the contractor brings its own contribution to the
building, its technological and organizational know-how. Also in this case, it
is essential to know how to interpret the different technical proposals, to be
able to govern and direct them toward the direction indicated by the original
idea; the same idea that is at the beginning of the path and that must also
become the final fulfillment: the starting point and the arrival.

\section{MIES VAN DER ROHE - GERMAN PAVILION FOR BARCELONA EXPO - 1929}

Conceived for the Exhibition Hall in Barcelona in 1929, the German Pavilion by Mies van der Rohe never held any exhibition. Its simple and quiet shape led the Exposition organizers to use it as a resting area. Along the various pavilions, the German one became a must-see course where architecture exhibits itself.

The preliminary sketch to the project for the Barcelona Pavilion expresses Miss's intentions in a complete and extremely effective way: abstract plans are composed to form a set where the 'wall box' is broken down into its basic elements.

The next study, which took place during the architectural and constructive design phase, demonstrates how the research is consistent with the main assumption. The dividing walls are 
extremely thin and apparently unrelated to each other. Due to the lack of executive drawings, we can only imagine the research done about the construction techniques that would guarantee the expected results.
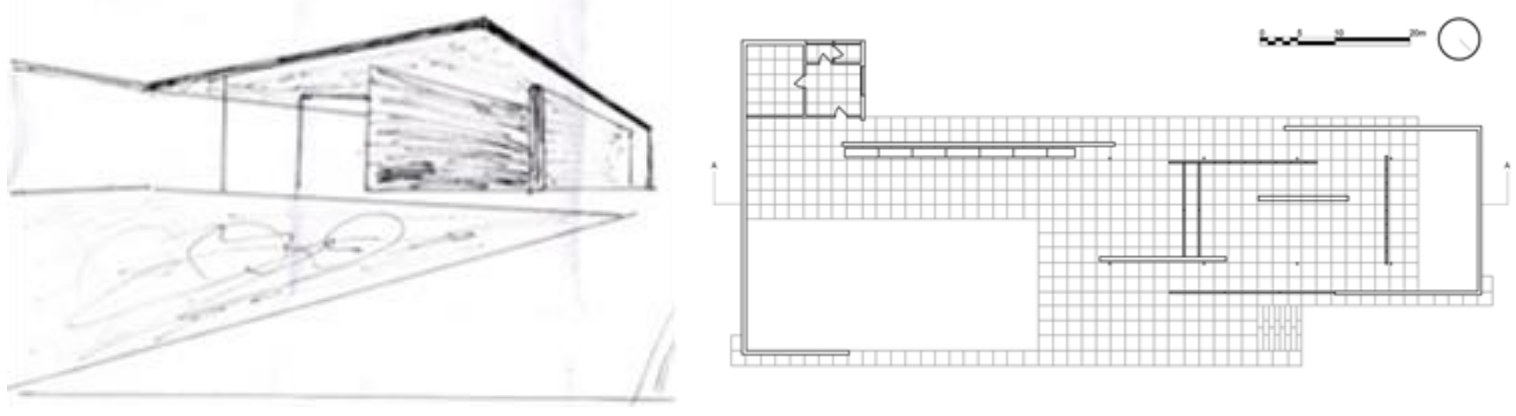

However, the procedure is evident by the continuous control during the whole construction of the architectural object, where the construction technology adopted for the realization perfectly agrees with the starting assumption. The partition walls are composed by a light metal frame on which are attached the stone slabs chosen by the designer. The final outcome shows abstractness equal to the initial scheme: the ideal composition of Mies becomes actual reality.
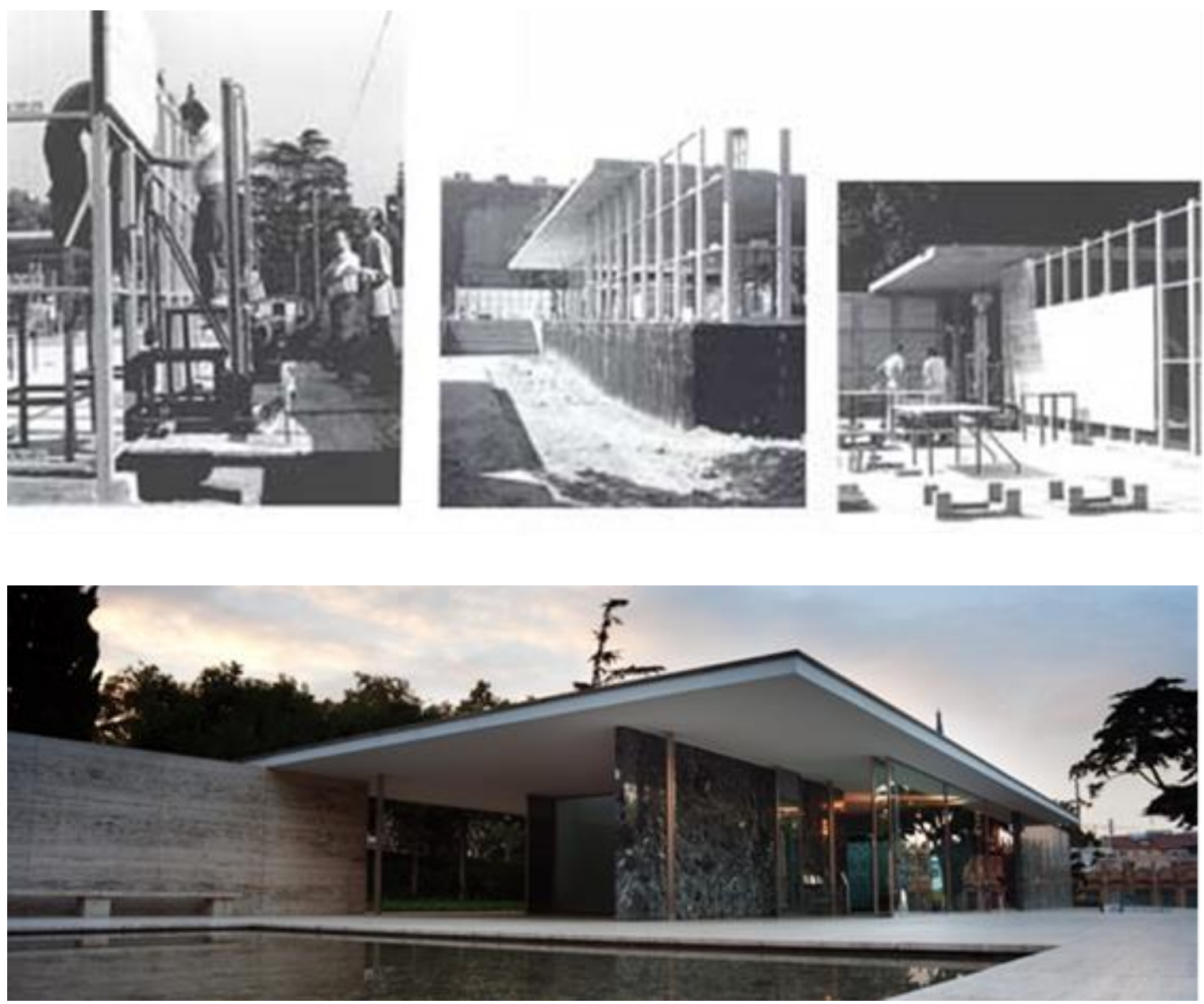


\section{LE CORBUSIER/XENAKIS/VARÈSE - PHILIPS PAVILION FOR BRUSSELS EXHIBITION - 1958}

Subject of Brussels Exhibition 1958 was supposed to be the Future, more precisely the direction taken by the technical progress. In the promoter Company's intentions the pavilion had to be conceived for performing a show of lights and sounds that should have conveyed this feeling without directly exposing the commercial products.

When Le Corbusier accepted the job, understanding the customer's intentions, he said that he would not deliver a pavilion, but a "Poème Electronique", a sort of Gesamtkunstwerk for the design of which he called engineers and musicians as Jannis Xanakisand and Edgar Varèse.

The Poem's basic idea was the representation of the history of human development from prehistoric times until the late fifties. Entering the pavilion, the visitor would have lost his look into a disturbing space, an aggressive void bounded by curved walls in an interior where architecture lose its connotations, to become an allegorical and apocalyptic show.

The first sketch is about a stomach, "... a stomach able of digesting 500 viewers/listeners and evacuate them at the end of the show, to make room for 500 more" [9].
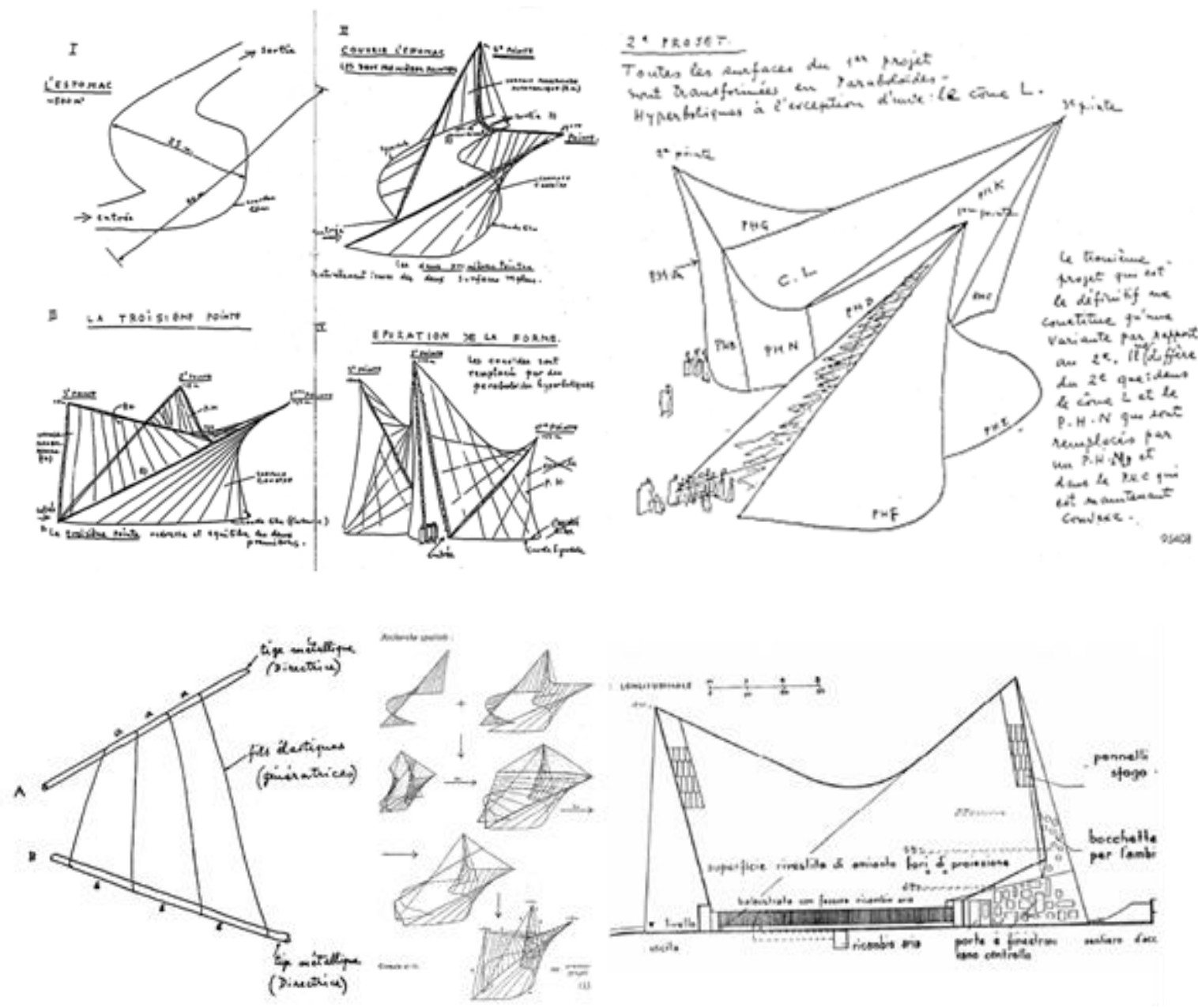

The evolution of the project idea is represented in the above reported sequence of sketches. From the top view shaped as a stomach composed by free curves, you go through the use of conoids, until the final proposal where the free curves became hyperboles and conoids are replaced by hyperbolic paraboloids. The project's development phase, being not yet available any kind of CAD technology, was faced with the aid of simple tools consisting of two rectilinear metal rods connected by elastic threads. The rods were used as guidelines and the wires as generators. The structure was also studied with the drawing and with structural 
models, to verify the bearing capacity of the chosen material (thin ribbed shells made by prestressed concrete, $5 \mathrm{~cm}$ of thickness).

The evolution of architectural design and structure goes step by step with the evolution of the musical and visual show. The image projection had to take place on a seamless wall, without interruption and with a curved shape, supposed to incorporate the viewer, in order to physically involve him in the show. Varèse created a musical composition that would have been repeated every eight minutes, introduced by a Xenakis overture.

Upon the completion of the project, several companies were invited to propose an appropriate technical solution for the construction of the pavilion. The Strabed company invented a construction system based on concrete slabs, of 1.0 square meters, prefabricated on work site and subsequently assembled in elevation. The slabs were curved and left for maturing on properly modeled piles of sand. The installation would have taken place by fixing each slab in the space between two nets of steel cables attached to the 'generator' poles. A sort of large tent, entirely self-supporting.

After a 1:25 scale model made with metallic generator pipes and wire mesh covered by plaster, the next phase was the realization, completed towards the end of 1957.
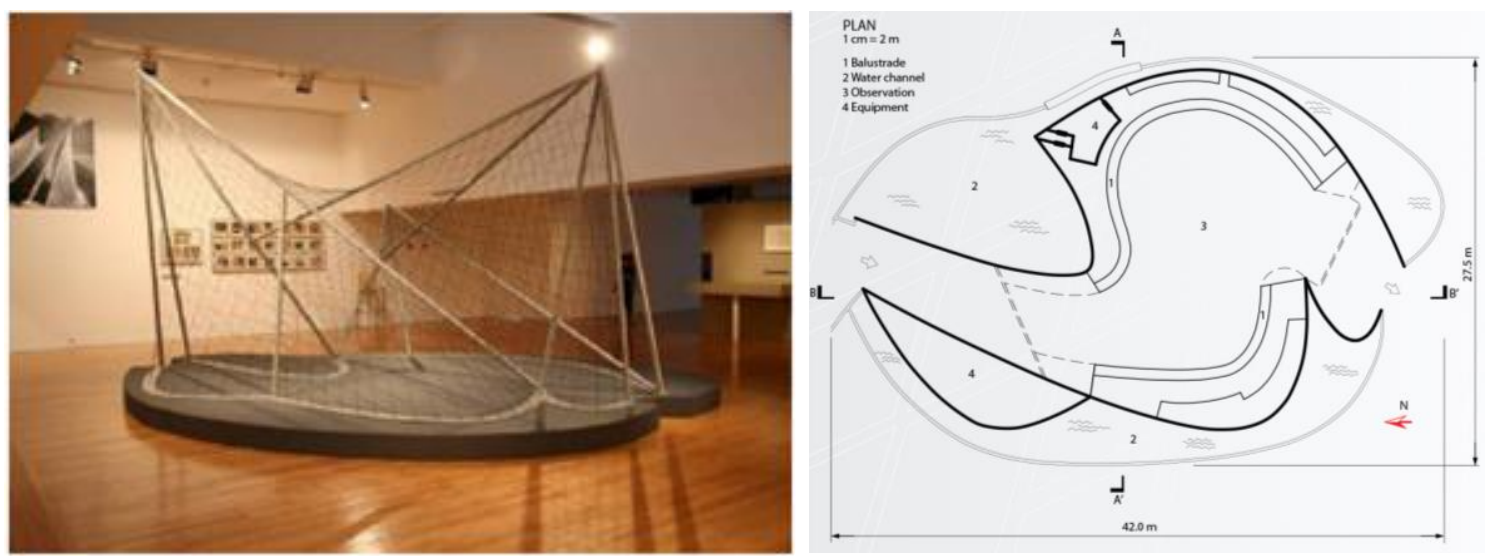

In order to realize the work exactly as it was conceived, to achieve the result imagined at the moment of conception, to make the object the closest as possible to what was originally envisioned, the construction techniques and the technology used were studied and analyzed with the fundamental contribution of the construction company. The group of designers, musicians and filmmakers worked in harmony toward the ultimate task, coordinated in any single step by Le Corbusier, as it is clearly testified by his sketches and declarations. The work of art was built in perfect harmony with the technical (and artistic) possibilities of the time completely put "at the service of the spirit" [10].

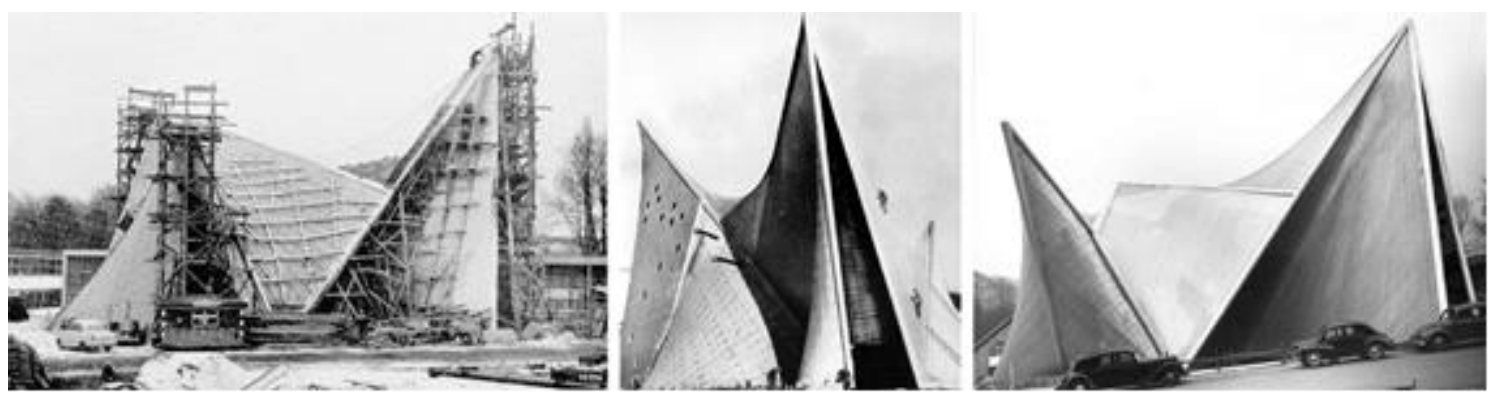

\section{ITO/BALMOND - SERPENTINE GALLERY LONDON HYDE PARK - 2002}

Since the year 2000, the Serpentine Gallery has commissioned a temporary summer pavilion in Kensington Gardens, London. Until now, so many leading architects from all around the world have been invited, from Zaha Hadid to Oscar Niemeyer, from Frank O. Gehry to Jean Nouvel and many others. In 2002 it was the turn of Toyo Ito

The initial idea of the project is inspired by the desire to create a completely free space, able to interact with the environment by letting the air, the light and the colors come in. An open space 
without columns and orthogonal patterns, a square box with a flat roof solely supported by perimetral supports.

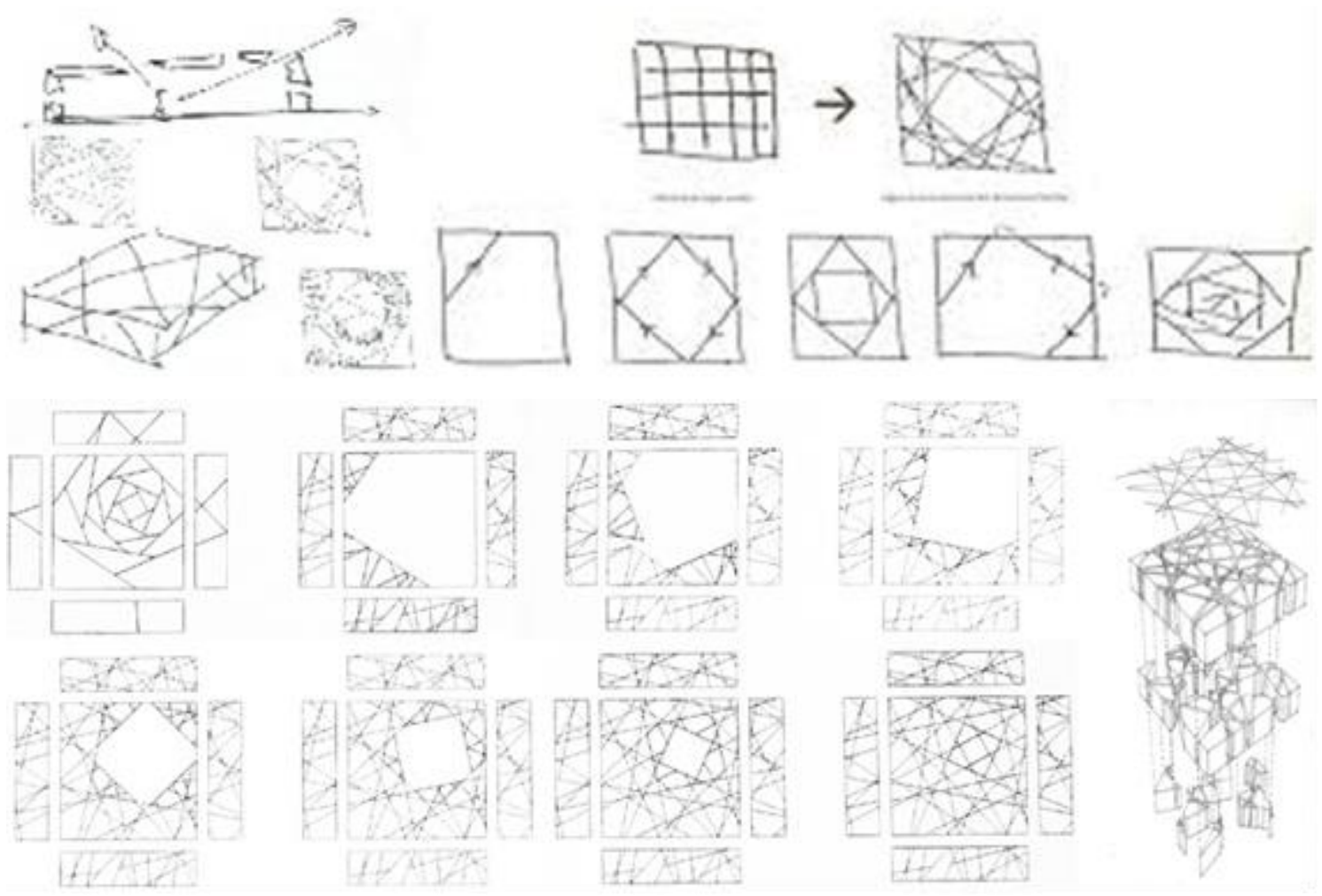

The starting scheme is made of infinite combinations generated by the rotation of a square. With the collaboration of Cecil Balmond, the initial sketch was developed using an algorithm that allowed the creation of a numerically controlled complexity. The control over the whole process, however, has not been fully delegated to the calculator, but it remained under the supervision of the architect Ito, who selected, among the infinite possible solutions generated by successive iterations and through specially crafted constraints, the form better representing its designing purposes. The digital medium has been placed at the service of the idea, not vice versa.

Subsequently, the ideograms processed by the computer were examined in an architectural project in which all the lines have been developed in a network formed by intersecting solids and voids in a seemingly chaotic pattern, but concretely (and digitally) controlled. In the architectural design, therefore, the guidelines became the grid of structural elements and the spaces generated by the interweaving of the lines themselves were closed with glass or solid panels of aluminum. At the same time, the structural verification started through dedicated software, which allowed to verify the choices made and give proper size to the flat-sectioned steel elements chosen for the structure. Each element is designed in detail by a software connected to numerical control machines, allowing to realize all the parts of the construction, ready to be assembled directly at the construction site.

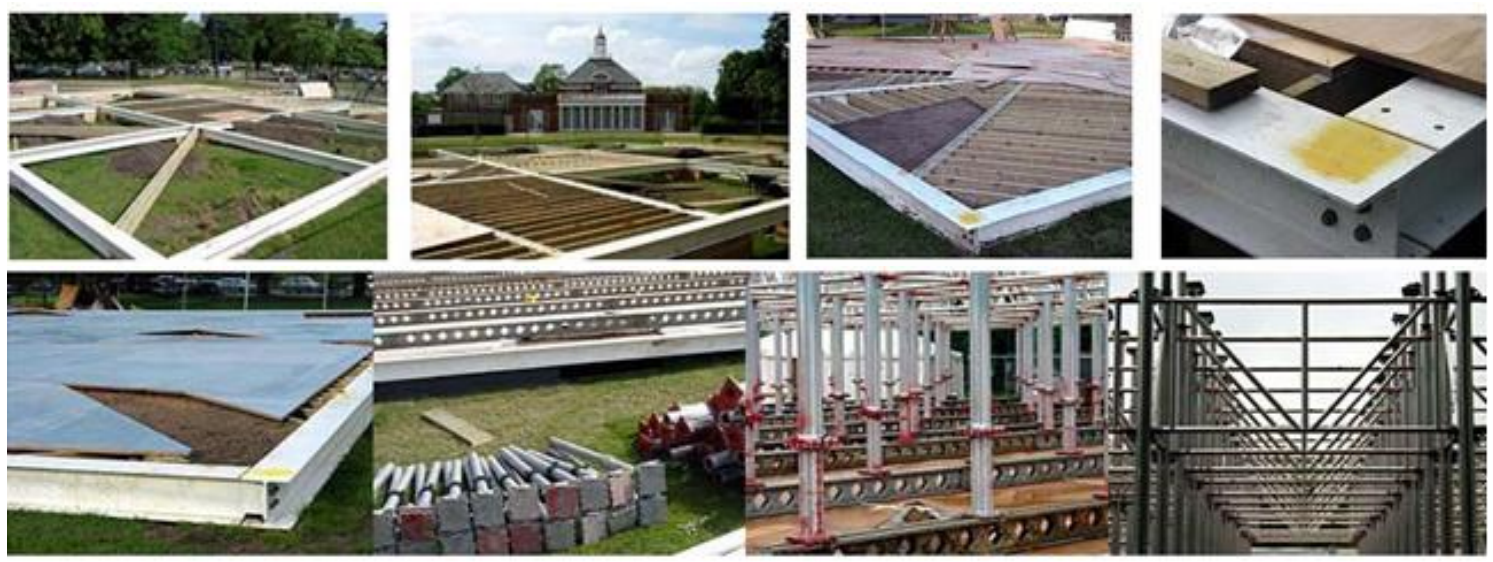



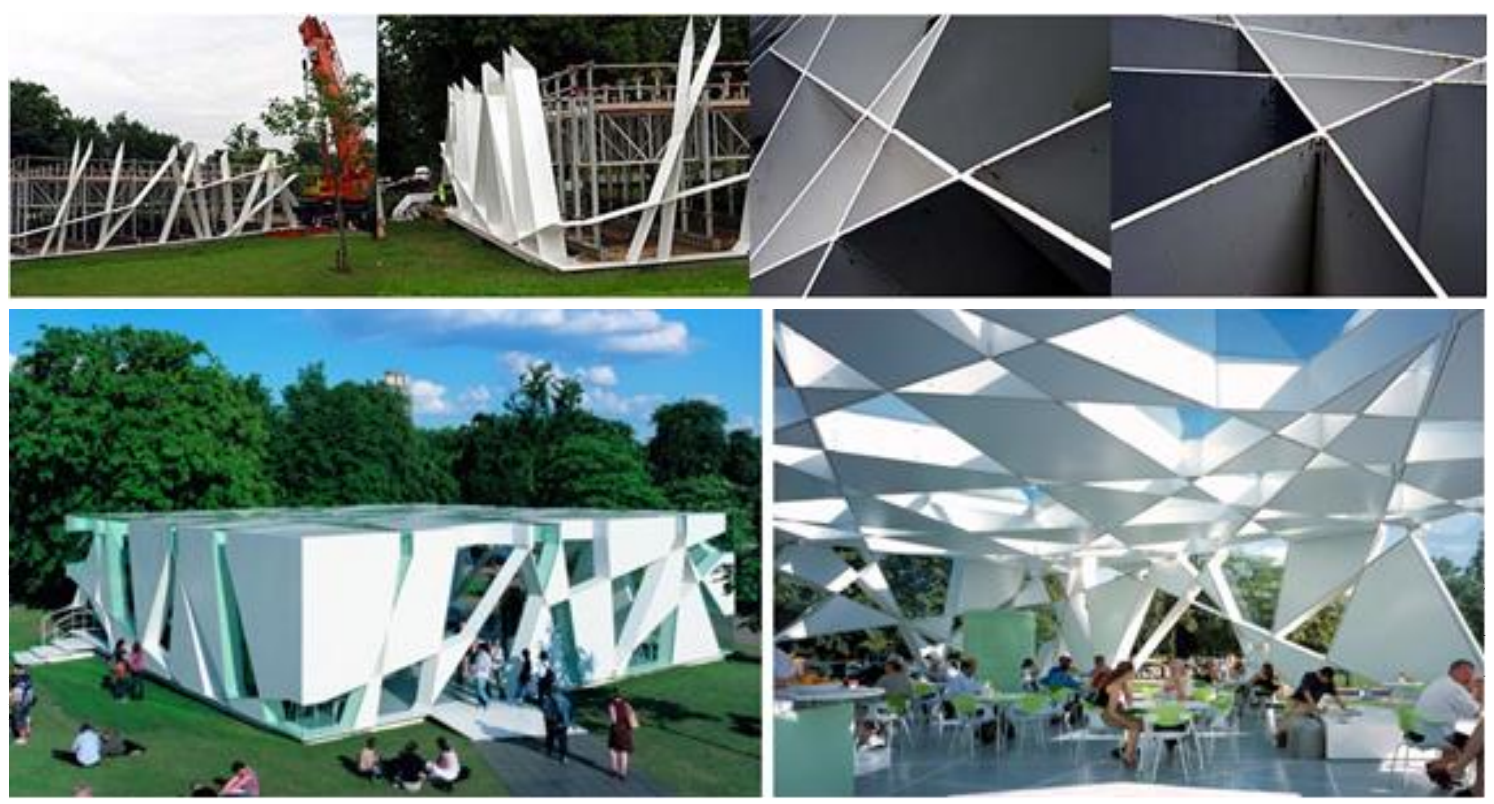

\section{FINAL REMARKS}

The examples here shown come to represent the evolution of the profession of the designer over the years, taking inspiration from the new demands generated by the technical discoveries and technological innovations. The control of all the constructive and spatial aspects of construction was virtually complete in Mies van der Rohe, who was able to autonomously coordinate the structural and technological variables, harmonizing them towards a single goal. Le Corbusier's example instead represents a group of professionals with mixed expertise; he coordinated towards a goal where technical components become too specialized to be directly controlled. Ito involves a leading numerical modeling expert to reach the desired result, but firmly retains the control of the final outcome by direct intervention in the choice of the best form.

In every instance, taking into account the due differences in approach and style, all the designers show the ability to 'bend' the construction techniques and the latest technologies to their objectives. Thus carrying out the apparently simple but extremely complex operation which allows to find synthesis in harmony.

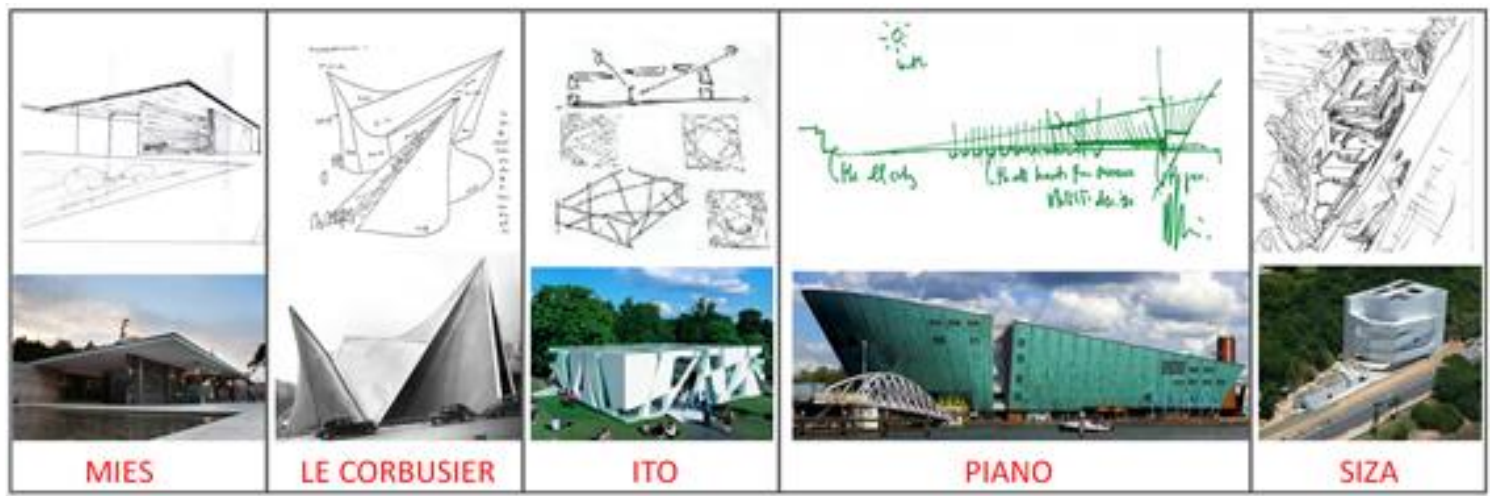

Referring to Heidegger's question about the current role of technical instrumentation [10]: it is necessary to dominate the technique not only from the instrumental point of view (t'́cnๆ), but

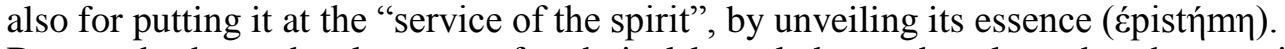

Due to the huge development of technical knowledge and tools, today the creativity is freer, from an instrumental point of view, and it seems like the designers are in the condition to definitely dominate the technique. But are they also able to put it at the "service of the spirit"? 


\section{REFERENCES}

[1] Boulez, P. 1979. Pensare la musica oggi. Torino: Einaudi.

[2] Brandi, C. 1967. Struttura e architettura. Roma: Accademia Nazionale dei Lincei.

[3] Capanna, A. 2000. Le Corbusier, Padiglione Philips, Bruxelles. Universale di Architettura. Torino: Testo \& Immagine.

[4] Capanna A., Cifariello F., Ciardi A., Del Monaco I., Gabrieli M., Ribichini L., Trovalusci G. 2012. Verso un'architettura sonora. Il Poème Électronique, Musica \& Architettura. Roma: Edizioni Nuova ultura.

[5] Gamboni, C. 2012. Toyo Ito e gli ingegneri, tre collaborazioni dopo Sendai. Firenze: Alinea Ed..

[6] Gregotti, V. 2010. Tre forme di architettura mancata, Torino: Einaudi

[7] Gregotti, V. 2008. Contro la fine dell'architettura, Torino: Einaudi.

[8] Le Corbusier, 1959. L'architecture et l'ésprit mathématique in AA. VV., La Métode dans la science modernes. Paris: Blanchard.

[9] Le Corbusier, 1960. L'Atelier de la recherche patiente. Paris: Editions Vincent.

[10] Heidegger, M. 1954. Die Frage nach der Technik in Vorträge und Aufsätze, Neske, Pfullingen. 1976. La questione della tecnica. In Saggi e Discorsi. Milano: Mursia.

[11] Rega, G., Trovalusci, P. 2002. Structuristes-constructeurs, structuristes-mathématiciens et...architectes-structuristes?. In A. Becchi, M. Corradi, F. Foce, \& O. Pedemonte (eds.), Towards a History of Construction: 455-473. Basel: Birkhäuser.

[12] Rega, G., Trovalusci, P. 2001. Strutturisti-costruttori, strutturisti-matematici e... architetti- strutturi sti?, Riflessioni sulle relazioni tra l' "arte del costruire", la meccanica (dei solidi e delle strutture) e la progettazione strutturale nell'architettura, Rassegna di Architettura e Urbanistica, 101/102, 134143.

[13] Trovalusci P., Panei R. 2010. Towards an ethic of construction: The structural conception and the influence of mathematical language in architectural design, in P. Cruz (ed.), Stuctures and Architecture, London (UK): Taylor and Francis, 53-54; on-line, 1-8.

[14] Trovalusci P., Tinelli A. 2010. Structural optimization vs. shape design, in P. Cruz (ed.), Structures and Architecture, London (UK): Taylor and Francis Group, 37-38; on-line, 1-8.

[15] Trovalusci P., Tinelli A. 2013. The recovery of the ethic of constructions: P. L. Nervi vs. S. Musmeci, two structural conceptions compared, in P. Cruz (ed.), Structures and Architecture, Lon don (UK): Taylor and Francis Group, 2013, 75-76; on-line, 1-8.

[16] Vitruvius (I sec. d. C.). De Architectura. 